AC 2012-3189: GOT RISK? THE ROLE OF RISK ANALYSIS IN HIGH SCHOOL EDUCATION

Ms. Eva Andrijcic, University of Virginia

Eva Andrijcic is a third-year Ph.D. student at the Department of Systems and Information Engineering at the University of Virginia. 


\section{Got Risk? The Role of Risk Analysis in High School Education}

\section{Introduction}

The purpose of this paper is to focus on an important aspect of systems engineering, namely risk assessment and management, and to present a case study of a class in which high school students were introduced to this topic through simple conceptual and graphical models, and through engaging hands-on activities. The paper is structured as follows. This section provides a brief overview of the class and its learning goals. Section two discusses in detail the individual lessons, learning goals, activities and methods. Section three presents sample results from student exercises, while section four discusses how students' progress was assessed. Section five presents concluding remarks.

Much has been written in the last two decades about the need to augment middle and high-school curricula by engineering classes ${ }^{1-5}$, but less focus has been placed specifically on integrating systems engineering ideas into the secondary school programs ${ }^{6-7}$. Risk assessment and management present important aspects of systems engineering, and they were chosen as the focus of an eight-day long class designed for three cohorts of $9-11^{\text {th }}$ grade students attending an academic summer camp. The aim of the class was to provide students with the knowledge and skills necessary to systematically identify possible sources of risk and ways to manage them, and in such a way to prepare them to become more critical problem solvers in the world of complex issues. The underlying idea that guided curriculum development was that students might learn better when they are able to apply what they learn in the classroom to everyday life, or to problems that are of interest to them. Thus, the area of risk assessment and management was chosen as appropriate since the related concepts and methods are applicable to everyday problems that teenagers are often faced with. As teenagers develop emotionally, socially and physically, they are increasingly exposed, individually and as a group, to a need to explore the boundaries of accepted norms and behaviors. In a sense, they are constantly and unconsciously performing risk analysis. By teaching them some basic concepts and simple models that are used in the field of risk-based decision making, students can be armed with the tools to more effectively and more consciously conduct risk analysis. The early exposure to the type of thinking required by the models discussed in this class promotes holistic, systems-based thinking for students possessing different levels of quantitative skills. By teaching students how to think critically and holistically about the issues that are relevant to them, we enable students to continue the learning process outside the classroom - we enable them to continually apply systems thinking to real life problems.

\section{Methods}

The Got Risk? class was taught in a 2011 summer academic camp to three cohorts of high performing $9-11^{\text {th }}$ grade students. The class was taught sequentially to the three cohorts over a 
six-week period. Each class was broken into six lessons that will be discussed in detail in this section. The overall goal of the class was to introduce students to the basic concepts of risk analysis and systems thinking, and to provide them with some basic tools through which they can holistically and systematically explore and analyze risk-based decision problems. Lessons were structured to emphasize the need for critical, systems thinking across different dimensions and students were encouraged to integrate and apply knowledge that they acquired in different classes, including math and science. This aspect of the curriculum addressed the apparent lack of knowledge integration across different classes at both the high school and undergraduate education $^{8-9}$. In order to promote the application of learned knowledge, students, organized in small groups, worked on a class project over the period of several days. Each day new elements previously learned in class were incorporated into the project. By working in groups, students were able to combine their multiple and sometimes differing perspectives to gain a more holistic and realistic view of the problem. Furthermore, through working in groups, students learned some communication and teamwork skills that are critically important in undergraduate engineering education and industry ${ }^{10}$.

The eight-day class was broken into six lessons. Lesson 1 addressed basic systems engineering and risk analysis concepts, and it related risk assessment and management to the larger systems engineering discipline. Students were asked to consider the meaning of the word risk, and to provide concrete examples of why we ought to care about assessing and managing risks. The overall goal of this lesson was to illustrate to students how risk analysis, as a major part of the overall systems engineering process, can help in the design, construction, management and maintenance of various systems, and how, on a more personal level, risk analysis can be used by students in their everyday lives to assess the risks, costs, and benefits of certain decisions they make. One of the main activities associated with this lesson was structured as a competitive oral quiz in which students had to guess the probability of consequences related to various events. Questions and answers were obtained from a special risk issue of the Discover magazine ${ }^{11}$. Questions included, among others,

- Can you guess the risk of dying from a volcano eruption?

- Can you guess the risk of contracting an infection while staying in a U.S. hospital?

- Can you guess the risk of an average U.S. teenager drinking hard liquor every day?

- Can you guess the risk of a young adult (aged 14 to 25) dying in a car crash?

This exercise was aimed at showing the students how easy it is to misinterpret the risks associated with certain events, without knowing all of the associated assumptions and without conducting proper risk analysis. Students were asked to rationalize their answers, and based on their responses, it was obvious that they struggled with understanding the concept of probability and how it is applied to real problems. Furthermore, their answers were constrained by the lack of information about the assumptions and factors that can influence events under consideration (i.e., they did not have a clear view of the big picture).

Lesson 2 focused in more detail on the process of risk assessment. The lesson dealt with identifying some difficulties in performing systematic risk assessment. Students were introduced to a method, the Hierarchical Holographic Model (HHM) ${ }^{12-13}$, that can be used to identify risks from a holistic, systems-based perspective. In particular, the HHM captures and represents the 
different dimensions of a system, and enables analysts and decision makers to identify the factors that influence, cause or shape risk from different perspectives (e.g., different stakeholder perspectives). A major result of the HHM process is the creation of a very large number of risk scenarios, organized into sets and subsets. Additionally, HHM can help identify most sources of risk and uncertainty ${ }^{12-13}$. Hall, in his seminal book Metasystems Methodology ${ }^{14}$ described the HHM as instrumental in understanding the diverse aspects of a complex problem, and for gaining an understanding of the system as a whole. After a brief introduction to the HHM, students participated in two group exercises. In the first exercise, students were asked to collectively construct an HHM that addresses the safety of the summer camp students. In particular, they were asked to identify anything that can affect the health and wellbeing of the summer camp students. Upon completion, they presented this HHM to the chief risk manager for the summer camp. In the second HHM exercise, students were given a magazine article discussing the consequences of the 2010 oil spill catastrophe in the Gulf ${ }^{15}$. Students were broken into two competing groups and each group was asked to construct a separate HHM that illustrates the factors associated with deep water drilling risks. The two groups compared their individual HHMs, discussed the differences and integrated their insights into a single, comprehensive HHM. Upon reflecting on the resulting model, students were asked to identify some conflicting stakeholder needs and objectives that are evident from the HHM. Students also identified some potential engineering options and policies that might be used to mitigate future risks and/or recover from endured consequences (e.g., plugging the well by triggering the failed blowout preventer, boosting workplace safety standards, keeping submarine robots and operating crews ready in case of emergencies). This was followed by a discussion of what additional information and knowledge would be necessary to design, construct and manage one such solution. Results of the two HHM exercises are discussed in Section 3.

In lesson 3 students were introduced to differences between quantitative risk assessment, which relies on probabilities to describe the likelihood of outcomes, and normative or value judgment risk assessment, which considers how safe is safe enough ${ }^{13}$. Students were introduced to two models that are used for quantitative risk assessment in some engineering disciplines, namely decision trees and fault trees ${ }^{13}$. These models were chosen, because they can be presented through their graphical dimension, and they can easily be scaled to account for the level of analytical and computational complexity. Students were taught that decision trees enable analysts and decision makers to more effectively and systematically choose between different courses of action, and to explore the range of risks and rewards associated with each possible solution alternative. Decision trees were introduced to students through two examples. The first example was a simple non-engineering problem that students could relate to, namely the choice of a college major that would maximize their expected earnings immediately following college graduation. A second, more advanced engineering reliability example was used to introduce the students to the foldback method associated with decision trees ${ }^{13}$. Fault trees were introduced to students as a method used in safety engineering and failure analysis, in which one can determine the probability of failure of a certain system by combining, through Boolean logic, the failure rates of the system's components ${ }^{13}$.

Lesson 4 focused on the process of risk management. Quantitative risk assessment, addressed in Lesson 3, was augmented with normative risk assessment which asks "How safe is safe enough?" and "What is an acceptable risk?"13. Students were introduced to the fallacy of the 
average expected risk approach, and to the importance of evaluating risks of extreme events. This was done through a series of simple exercises in which students were asked to consider whether they would personally be more concerned with an event that is fairly likely to happen but will cause relatively small consequences, or with an event that is unlikely to happen, but could cause catastrophic damages. Students were introduced to the idea that the ultimate goal of risk-based decision-making is to avoid the catastrophic risks and consequences, and that the average expected risk (resulting in positive or negative consequences) should not be used as the sole criterion in risk-based decision making. Through classroom discussion, students recognized that the process of risk management is critically important for managing systems, especially large, complex engineered systems. They also recognized that the process of risk management is not always a straightforward process, and that risk management options are limited by budgetary and other constraints imposed by different decision makers and stakeholders. Students were introduced to the idea that when managing large systems, the best way to make a decision is to assess the associated costs, benefits and risks of all alternative solutions, and to identify and enumerate any and all sources of uncertainty. As a part of Lesson 4, students participated in a field trip to a decommissioned nuclear research reactor where they had the opportunity to tour the facility and speak to the facilities manager, a former nuclear engineer. Students were encouraged to ask risk assessment and management related questions. Their questions prompted discussions on how important risk management was to the facility when it was still in operation and in general how important risk management is to the nuclear engineering industry, what risk assessment models (e.g., fault trees) were used by the engineers and researchers working in the facility, and what may be some potential consequences of a nuclear reactor failure.

Lesson 5 focused on the process of risk communication, and the importance of having a good 'analyst - decision maker - stakeholder' communication in systems engineering and risk management. Students learned about the role of risk communication, the major steps of public risk communication, characteristics of effective risk communication messages, and about the difficulties associated with effectively communicating risks to the affected stakeholders. This was achieved through two exercises. In the first exercise, students were asked to individually read one of the three newspaper articles related to the 2011 nuclear reactor crisis in Japan ${ }^{16-18}$. They were asked to identify the sources, recipients and modes of risk communication, and factors that might have made the particular instance of risk communication inefficient. They were then grouped into three groups and asked to present their findings to the rest of the class and to propose some concrete steps in which the particular instance of risk communication could have been improved. In the second exercise each of the three groups was given a different onesheet summary covering different research findings related to risk communication and risk perception, and groups were required to teach that information to the rest of the class by any means they found entertaining or memorable. These methods of instruction ranged from skits, to illustrations, to poems and raps. The students then related the steps of efficient risk communication to the newspaper articles on the nuclear crisis ${ }^{16-18}$, and they either confirmed their initial suggestions on how to improve the risk communication process addressed in the articles, or they refined them with more sophisticated ideas learned from the summary sheets.

Lesson 6 was a summary session in which students presented their group projects to an audience of peers and teachers. Students were broken into groups of four and required to present an original project of their choosing that integrated some of the concepts and models that they 
learned in class. While students were given the liberty to choose a problem of their liking, they were limited to choosing problems that required risk-based decision-making. The selected projects included among others, exploring the effects of McDonalds Monopoly games on the rates of obesity in the U.S., the choice of participating in sorority life in college, the choice of a varsity sport that minimizes the risk of injuries, assessing the health risks of smoking, and assessing the risks of skydiving. Students were required to apply the Hierarchical Holographic Model, and were given the choice of applying either the decision or fault tree model. They were also required to consider how the associated risks could be communicated to the relevant stakeholders. In the process of completing this project, students were required to list all data and modeling assumptions, and their data sources. Each group received individual support from the teacher, who helped them form the question they wished to explore, identify the needed data and available data sources, form necessary assumptions and apply the learned models to their problems. All students participated in the creation of an assessment rubric that covered categories including, among others, the design and relevance of the poster, effectiveness of oral presentation, relevance and clarity of information, quality of sources of information, validity of the use of risk models, and the quality of modeling assumptions. Based on these categories, the students and the teacher evaluated each poster and provided positive and constructive criticism aimed at improving the quality of the poster and the presentation.

\section{Results}

The main goals of this class were to: (i) equip students with the knowledge and skills necessary to systematically and holistically identify the possible sources of risk and ways to manage them, so that they could become more critical problem solvers; (ii) illustrate to students how the knowledge and skills acquired in this class can be transferred to risk-based decision making in their everyday lives, as well as to more complex engineering related problems. This section discusses a sample of the results that were obtained in the Got Risk? class.

The Hierarchical Holographic Modeling (HHM) exercises were aimed at improving the students' ability to apply systems thinking, and to identify a wider set of factors that might influence or shape risk. The first HHM exercise required students to identify all perspectives from which they can assess the safety of the summer camp students, and within each perspective, to list factors that might shape or cause the risk to the safety of students. The HHM created by one of the three cohorts is shown in Figure 1. It reflects a diversity of risks that the students are exposed to, including risks associated with attending classes, risks associated with interacting with other students, teachers and counselors, and physical risks associated with the nearby construction projects. The construction of this HHM bewildered many students who were overwhelmed by the number of factors that could be considered in a comprehensive risk analysis. Students discussed their concerns with the camp's risk manager who talked about how the knowledge of these risk factors can help her prepare for potential emergencies and allocate budget to appropriate risk prevention and mitigation efforts. Since the topic of the second HHM exercise was much more complex and less familiar to the students, they openly recognized the value of an HHM in systematically and jointly identifying the risk factors associated with the risks of deep water drilling. Different students contributed different ideas to the model, these ideas were debated and evolved, and jointly the students created a comprehensive, big picture view of the problem. The resulting HHM is shown in Figure 2. When comparing students' initial thoughts 
generated without the use of the HHM with the results of the HHM, the later shows a much higher level of sophistication and detail, and shows a deeper concern for the various stakeholders and constraints imposed on the problem.
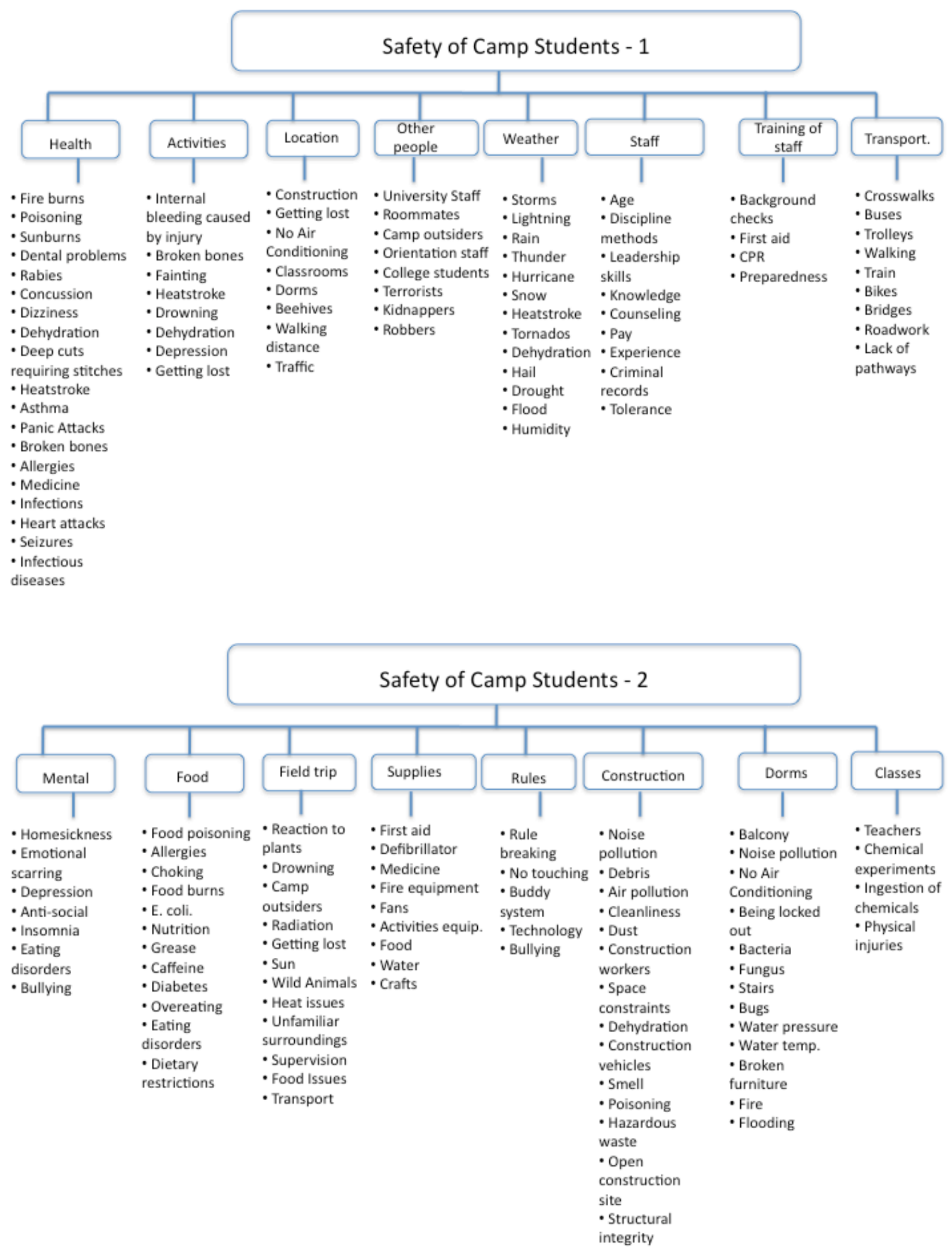


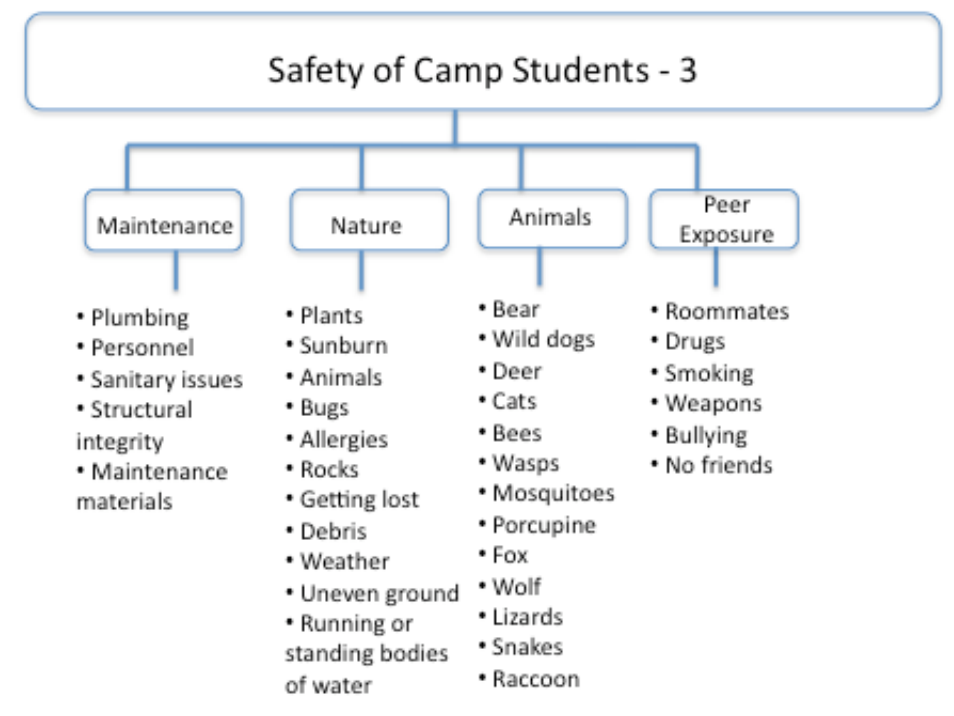

Figure 1: Hierarchical Holographic Model (HHM) listing the factors that influence and shape risks to summer camp students

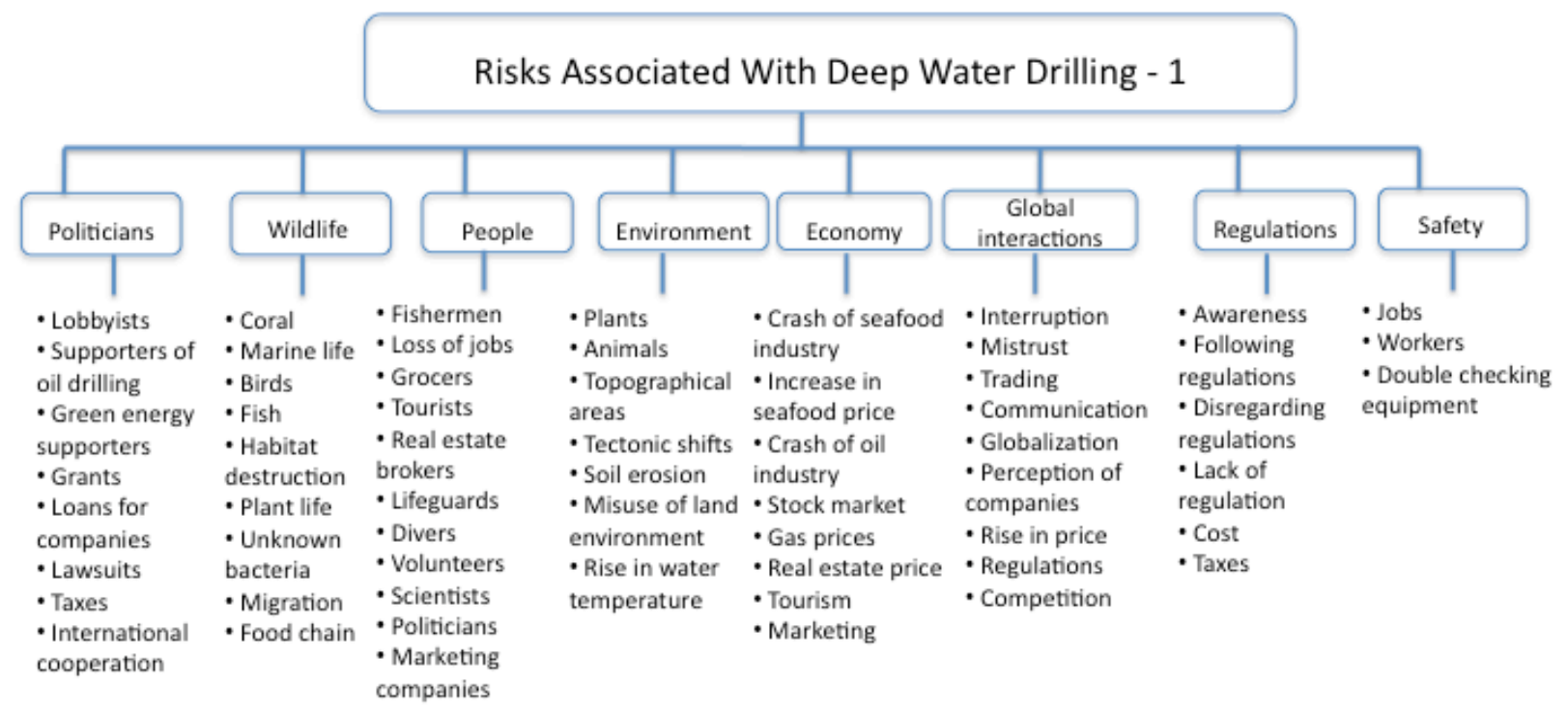




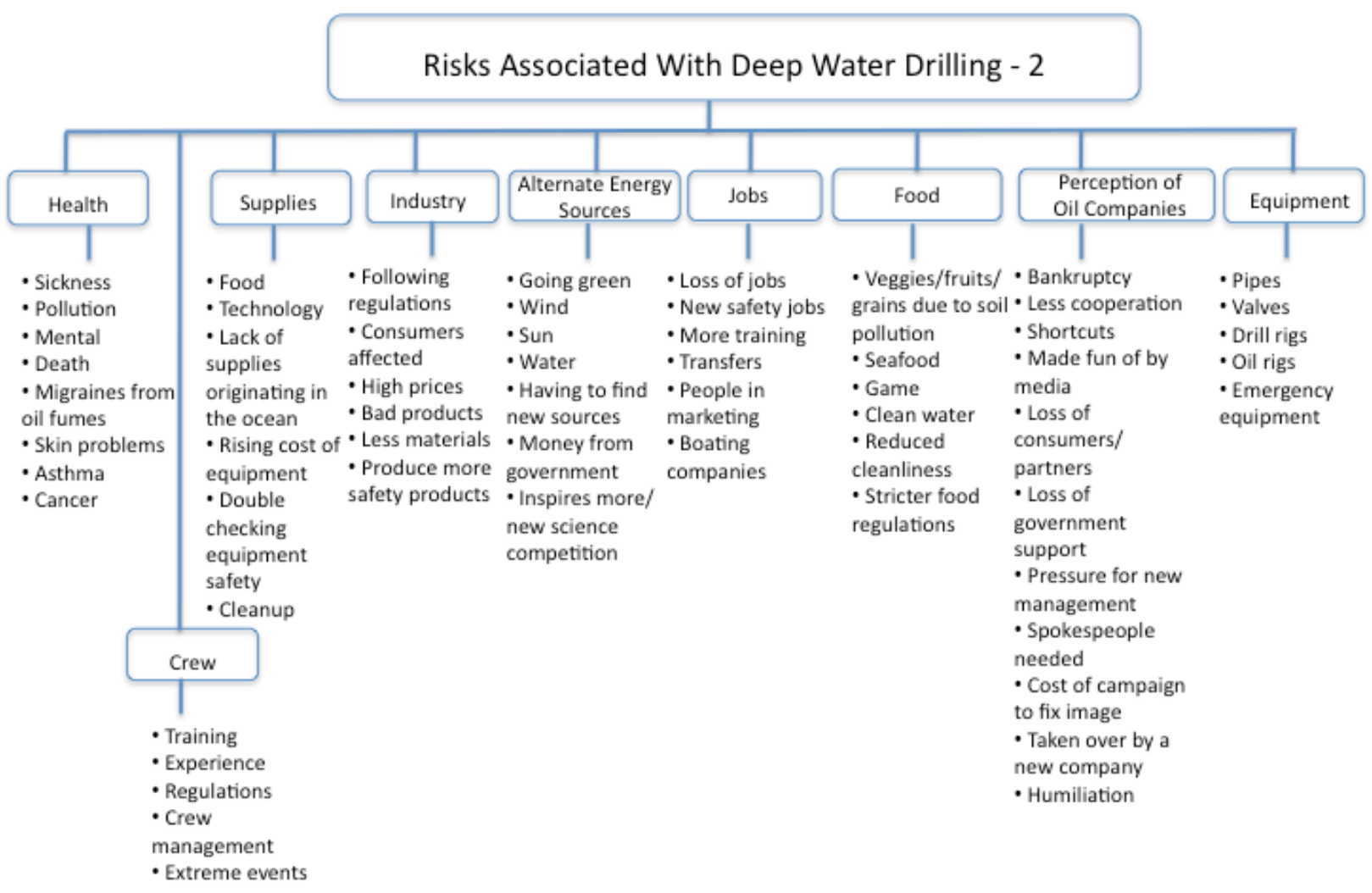

Figure 2: Hierarchical Holographic Model (HHM) listing the factors that influence and shape risks associated with deep water drilling

In the risk communication exercise, covered in Lesson 5, students were asked to critique newspaper articles related to Japan's nuclear crisis ${ }^{16-18}$ based on what they learned about the proper aspects of risk communication. Students were given a summary sheet detailing the major points of good risk communication, but in their oral analysis of the newspaper articles, they drew not only from the summary sheet, but also from their personal experiences. They discussed which of the aspects of proper risk communication they would have liked to hear in cases of emergency (e.g., tornadoes, hurricanes), and which were realistic given the overall situation. Through reading those newspaper articles, students reflected upon their new ability to not take written words for granted, but to consider the bigger picture surrounding the problem.

\section{Assessment}

Students were assessed through individual short reflection papers, through daily group activities, and through a final group project in which they were required to (i) apply the concepts and models learned in class to a risk-based decision problem of their choice, and (ii) present their projects to a group of peers and teachers. 
Assessment conducted in the Got Risk? class was purely formative ${ }^{19-21}$. Since the class was taught to three consecutive cohorts of students, this formative evaluation enabled the later students to benefit from the comments made by the earlier students, as instruction was regularly modified to reflect students' concerns and suggestions. Students were evaluated in several ways. First, students were required to write several brief reflection papers in which they were asked to: (i) discuss the most important point that they learned in a particular class and how it might be applicable to their personal lives, and (ii) identify any concepts that were still unclear to them. Students' responses were reviewed and any pending issues were discussed in the following class. Additional examples were provided to further explain the problematic concepts. The first cohort of students used the one-minute paper format to express their inability to comprehend the fault tree examples and the abundance of math involved in computing the probability of failure of the top event. They were provided with another, simpler example, which clarified some confusion. This simpler example was used to teach the other two cohorts, and the later classes understood the basic construct, application and computations involved in fault trees much faster. The oneminute paper format was also useful to track the students' thoughts on how they might be able to apply some of the ideas learned in this class to their personal lives. A few students indicated that while they might not be interested in the quantitative portion of the class, they were very interested in the psychology of how people understand risk. Overall, through these papers students showed fairly high levels of interest in the topic and its potential use to real life problems. The concerns identified by the first cohort of students (which were mainly to do with how one goes about calculating the probabilities of an event happening, and the mathematics involved in fault trees) were addressed immediately and instruction was modified, so that later cohorts showed a much lower level of concern for those topics.

The second form of assessment was through the use of student-generated field trip questions. Before the field trip students were asked to write down three questions that relate the concepts they learned in class to the nuclear power industry. The teacher reviewed these questions and provided written constructive comments to students. Students were then encouraged to ask at least one of their questions during the field trip. This type of evaluation gave the students an opportunity to evaluate all of the course topics that they covered, and to reflect on what they understood.

The third form of assessment was associated with the final group projects. Before commencing work on their final projects, students were shown examples of good and bad past projects to give them a sense of the level of performance that was expected of them. Students then participated in constructing an evaluation rubric that would allow them and the teacher to compare the different projects and to provide presenters with detailed feedback that will help them improve their future performance ${ }^{22}$. The resulting rubric considered a range of factors that students considered important, including the look of the poster, the quality of the oral presentation, the quality of the information and the appropriate use of concepts and models learned in class. After being given positive and constructive comments on their poster and their presentation, presenting students had the opportunity to reflect on the criticism, and many of them gave very specific ideas of how they would further the project if they had more time to work on it. 


\section{Conclusion}

Overall, majority of participating students expressed high interest in the topics that were covered in class, and performed well on all in-class assignments. Through their short reflection papers and their final projects, students identified ideas that they might be interested in exploring further with the methods and concepts they learned in this class. By comparing the students' questions, responses and general insights over the 8-day period, it was obvious that the concepts and methods taught in this class enabled students to apply a more holistic and systematic though process, and to identify the bigger picture associated with the problem. This was true for students possessing higher and lower levels of quantitative skills. In their reflection papers and through classroom discussions, several students identified problems in their everyday life that they could assess through the use of the concepts and methods they learned in class. Upon leaving the camp, students were encouraged to continue critically assessing risk-related stories in newspaper articles, and to continue identifying concepts learned in other classes that could help them solve everyday risk-based decision problems.

\section{Bibliography}

1. Sadler, P.M., H.C. Coyle, M. Schwartz. Engineering Competitions in the Middle School Classroom: Key Elements in Developing Effective Design Challenges. The Journal of the Learning Sciences, Vol. 9, No. 3, 2000: pp. 299-327.

2. Richards, L.G., G. Laufer, and J.A.C. Humphrey. Teaching Engineering in the Middle Schools: The Virginia Middle School Engineering Education Initiative. Frontiers in Education Conference Proceedings. FIE 2002, Boston, Massachusetts, 2002. http://fie.engrng.pitt.edu/fie2002/papers/1530.pdf

3. Jeffers, A.T., A.G. Safferman, and S.I. Safferman. Understanding K-12 Engineering Outreach Programs. Journal of Professional Issues in Engineering Education and Practice. Vol. 130, No. 95, 2004: pp. 95-108.

4. Cunningham, C.M., and K. Hester. Engineering is Elementary: An Engineering and Technology Curriculum for Children. Proceedings of the 2007 American Society for Engineering Education Annual Conference \& Exposition, American Society for Engineering Education, 2007.

5. English, L.D., L. Dawes, P.B. Hudson, and T. Byers. Introducing Engineering Education in the Middle School. Proceedings of the Research in Engineering Education Symposium 2009, 20-23 July 2009, Palm Cove, Cairns.

6. McKay, M., D. Brockway, E. McGrath, H. Harms, E. Hole, and D. Janosz. Systems And Global Engineering: Results Of A Pilot Study For High-School Students And Teachers. American Society for Engineering Education Annual Conference, Austin, TX, June 2009.

7. Seymour, S. J. and R.R. Luman. Academic Perspectives of Systems Engineering. Johns Hopkins APL Technical Digest. Vol, 29, No. 4. 2011: 377 - 386.

8. Fromm, E.. The Changing Engineering Educational Paradigm. Bernard M. Gordon Lecture. National Academy of Engineering, October 6, 2002. Available online at:

http://www.gatewaycoalition.org/highlights/files/NAE_PAPER/NAE_PAPER.PDF 
9. Ambrose, S.A., M. W. Bridges, M. DiPietro, M. C. Lovett, and M. K. Norman. "How Learning Works: 7 Research-Based Principles for Smart Teaching.” Jossey-Bass, San Francisco, 2010.

10. Chan, A.D.C., and J. Fishbein. A Global Engineer for the Global Community. The Journal of Policy Engagement. Vol. 1, No. 2, 2009: pp. 4-9.

11. Discover Magazine: The Science of Risk. A Fistful of Risks. May 1996.

12. Haimes, Y.Y.. Hierarchical Holographic Modeling. IEEE Transactions on Systems, Man and Cybernetics. Vol. 11, No. 9. 1981: pp. 606-617.

13. Haimes, Y.Y.. "Risk modeling, Assessment, and Management," Third Edition. John Wiley \& Sons, New Jersey, 2009.

14. Hall, A.D. III. "Metasystems methodology: A new synthesis and unification." Pergamon Press, New York, 1989.

15. Margolis, M. 4.4 Million Barrels Later. Discover Magazine. Jan/Feb 2011.

16. Fackler, M.. Radiation Fears and Distrust Push Thousands From Homes. New York Times. March 17, 2011. Available at: http://www.nytimes.com/2011/03/18/world/asia/18displaced.html?pagewanted=all.

17. Srivastava, M. and S. Sato. Conflicting Information Drives Anxiety in Japan Nuclear Crisis. Bloomberg. March 17, 2011. Available at: http://www.bloomberg.com/news/2011-03-17/conflicting-information-drives-anxiety-injapan-nuclear-crisis.html.

18. Tabuchi, H., K. Belson, and N. Onishi. Deart of Candor From Japan's Leadership. New York Times. March 16, 2011. Available at: http://www.nytimes.com/2011/03/17/world/asia/17tokyo.html?pagewanted=all.

19. Wiggins, G.. "Educative assessment: Designing assessments to inform and improve student performance." Jossey-Bass, San Francisco, 1998.

20. Crooks,, T.. The Validity of Formative Assessments. British Educational Research Association Annual Conference, University of Leeds, September 13-15 2001.

21. Wiliam, Dylan (2006). Formative assessment: getting the focus right. Educational Assessment. Vol.11, No.3\&4, 2006: pp. 283-289.

22. Andrade, H. G.. Understanding rubrics. Educational Leadership. Vol. 54, No. 4, 1997: pp. 14-17. 